\title{
Do uno ao diverso: breve histórico crítico do comparatismo
}

\author{
Eduardo Faria Coutinho
}

RESUMO: The article deals with the comparative literature studies in their first century of existence, from their earliest manifestations, when it was not yet considered an academic subject, to the works that consolidated it in the modern studies, especially the work of Hutcheson McCauley Posnett. The article also mentions Wellek's criticism to the studies based on the French School, and it finally adds some considerations about the interdisciplinary studies developed in the last two decades.

PALAVRAS-CHAVE: literatura comparada, Wellek, escola francesa, escola americana, relações interliterárias e interdisciplinares.

Se lançarmos uma breve mirada sobre a história da Literatura Comparada como disciplina acadêmica, verificaremos, neste conturbado ocaso do século XX, que ela é a história da passagem de um discurso coeso e unânime, com forte propensão universalizante, para outro plural e descentrado, situado historicamente, e consciente das diferenças que identificam cada corpus literário envolvido no processo da comparação. Marcada no início por uma perspectiva de teor historicista, calcada em princípios científico-causalistas, decorrentes do momento e contexto histórico em que se configurara, e em seguida por uma ótica predominantemente formalista, que conviveu, entretanto, com vozes dissonantes de significativa relevância, a disciplina atravessou seu primeiro século de existência em meio a intensos debates, mas apoiada em certos pilares, de tintas nitidamente etnocêntricas, que pouco se moveram ao largo de todo esse período. Nas duas últimas décadas, contudo, dos anos 70 para o presente, a importância crescente da Teoria Literária e dos chamados estudos pós-colonialistas, abalaram o cerne da Literatura Comparada, aproximando-a cada vez mais de questões como a da identidade cultural e nacional, e deslocando o seu foco de atuação para fora do eixo constituído pela Europa Ocidental e a América do Norte. De olho nessa mudança, para nós crucial, procederemos a seguir a uma breve revisão crítica do comparatismo em seus momentos mais expressivos,

Professor de Literatura Comparada da UFRJ 
com o fim de tecer indagações sobre as implicações por ela ocasionadas no que concerne ao estágio atual da disciplina.

$\mathrm{O}$ uso de se comparar literaturas nacionais teve origem muito antes de a Literatura Comparada ser reconhecida como uma disciplina regida por certos princípios e métodos. No entanto, é só no século XIX que ela começa a instituir-se como área do saber e a definir seus rumos e objetos de atuação. Num rastreio ao velho hábito da comparação, por momentos distintos da história literária, todos anteriores à sua configuração como disciplina, avultam exemplos que, significativos, merecem registro. Já na Antigüidade, especialistas como Berossos ou Filon de Biblos eram versados em duas literaturas, tendo escrito sobre ambas. Os mesmos mitos freqüentavam diferentes literaturas e os mitógrafos comparavam textos de comunidades diferentes, criando seus próprios heróis tribais a partir de mitos anteriores. $\mathrm{Na}$ Roma Clássica, autores como Macrobius e Aulus Gellius teceram diversos paralelos entre poetas romanos e gregos; e, na Renascença, o comparatismo chegou a tornar-se moda na Europa, devido, em grande parte, à doutrina da imitação, que exigia comparações e o estudo de influências. No século XVIII, a comparação entre obras literárias clássicas e modernas voltou a ocupar um primeiro plano, gerando inclusive a famosa Querela dos Antigos e dos Modernos, e, finalmente, após essa época, inúmeros foram os casos isolados de escritores ou críticos que, marcados por acentuado senso de cosmopolitismo, realizaram estudos comparativos de autores, obras, movimentos, ou até literaturas de maneira geral: Goethe, Herder, Lessing, Mme. de Staël, os irmãos Schlegel, Henry Hallam e Sismondi.

No século XIX, à diferença do que ocorrera até então, surge necessidade de sistematização do comparatismo e a Literatura Comparada principia a erigir-se como área do conhecimento. É a época de grande fé na ciência, em que o empirismo e o método indutivo desempenham papel de relevo, e a disciplina não deixará de portar essas marcas, só muito mais tarde postas em questão. É também a época em que se incrementa o pensamento cosmopolita e se amplia o interesse por culturas que fogem ao eixo europeu. As línguas despertam intensa curiosidade e tornam-se objeto da Lingüística Comparada. A Literatura começa a ser encarada por uma ótica conscientemente comparatista, e surgem os primeiros cursos e estudos sobre o assunto. Um quadro exaustivo dos passos da Literatura Comparada em sua fase de afirmação e autodefinição escaparia sem dúvida ao âmbito deste trabalho, mas expressivas, ainda que breve pinceladas, não devem tampouco ficar à margem. Seguem-se, assim, algumas delas. Em 1816, antes ainda da grande voga cientificista, Noel e Laplace publicam na França uma série de antologias de diversas literaturas, sob o rótulo genérico de Curso de Literatura Comparada, e entre 1828 e 1840, o termo aparece empregado na obra Panorama da Literatura Francesa do século XVIII, do Professor AbelFrançois Villemain, que, já em 1828-29, ministrara na Sorbonne um curso sobre o assunto. Em 1830, J. J. Ampère refere-se à história comparativa das artes e da literatura em seu Discurso sobre a história da poesia, e, dez anos 
depois, reemprega o termo no título da obra História da Literatura Francesa comparada às Literaturas Estrangeiras. Em 1835, por fim, Philarète Chasles se encarrega de formular alguns princípios básicos do que considerava ser uma história da literatura comparada, e parte para propor uma visão conjunta da história da literatura, da filosofia e da política nos cursos que irá ministrar, em 1841, no Collège de France ${ }^{1}$.

Embora as obras mencionadas tenham na realidade muito pouco do que mais tarde se veio a compreender como Literatura Comparada - o estudo de Noel e Laplace, por exemplo, não passa de uma coletânea de textos escolhidos, sem nenhuma preocupação sequer com o confronto, e o Panorama do Professor Villemain não contém mais do que breves referências a outras literaturas fora das fronteiras da França - elas expressam ao menos uma consciência da necessidade de constituição da disciplina e de sua legitimação, pela cunhagem do termo para designá-la. Tal preocupação, porquanto mais presente na França, conforme se verifica posteriormente na Revue des Deux Mondes, de Saint-Beuve, e em seus Noveaux Lundis (1884), não deixa, todavia, de figurar, e com vigor inegável, em textos de autores oriundos de outras nações do Ocidente Europeu. Na Alemanha, Moriz Carrière já adota, em 1854, no livro Das Wesen und die Formen der Poesie, a expressão vergleichende Literaturgeschichte, mais tarde difundida como vergleichende Literaturwissenschaft; e, na Itália, De Sanctis já leciona a disciplina em Nápolis, em 1863, e Mazzini declara em seus Scritti (1865-67) que nenhuma literatura pode alimentar-se de si mesma ou escapar à influência de literaturas estrangeiras ${ }^{2}$. Na Grã-Bretanha, em 1886, surge o livro Comparative Literature, da autoria de Hutcheson McCauley Posnett ${ }^{3}$, que, apesar do enfoque adotado, de cunho predominantemente sociológico, é até hoje conhecido como o primeiro, em língua inglesa, dedicado exclusivamente à matéria.

Esta fase inicial, designada pelos teóricos mais recentes de préhistória da Literatura Comparada, evolui, da última década do século XIX até meados do século XX, para um momento de certa efervescência, em que a disciplina penetra no meio acadêmico, tornando-se objeto de ensino em universidades européias e norte-americanas e dotando-se de bibliografia específica e publicações especializadas. É então que surgem as primeiras cátedras universitárias: Lyon (1887), com Joseph Texte, Sorbonne (1910), com Fernand Baldensperger, e, em seguida, J. M. Carré, na França; Harvard (1890), com Arthur Richard Marsh, e, mais tarde, com H. C. Schoffield e Irving Babbit, e Columbia (1899), com George Woodberry, nos Estados Unidos. É então também que se publica a primeira bibliografia sobre o assunto, de Louis Betz, com o título La littérature comparée: essai

\footnotetext{
${ }^{1}$ Ver CLEMENTS, Robert J. Comparative Literature as Academic Discipline. New York, MLA, 1978 e WEISTEIN, Ulrich. Comparative Literature and Literary Theory. Bloomington, Indiana Univ. Press, 1973.

2 Ver nota 1.

${ }^{3}$ POSNETT, H. M. Comparative Literature. (1886); rpt New York, Johnson Reprints, 1970.
} 
bibliographique ${ }^{4}$ (1900), marco de consolidação do termo Literatura Comparada, e base da famosa Bibliography of Comparative Literature ${ }^{5}$, de Fernand Baldensperger e Werner Friederich, dada a público cinqüenta anos depois e considerada como o início dos modernos estudos da disciplina. É ainda desse período que datam a Revue de Littérature Comparée (1921), criada por F. Baldensperger e Paul Hazard, e durante longos anos o principal veículo de divulgação de trabalhos na área, e o manual de Van Tieghem, La littérature comparée (1931) ${ }^{6}$, adotado em todos os principais centros de ensino da matéria. Estas duas últimas publicações, bem como os demais manuais que a este se seguiram com o mesmo título - os de François-Marius Guyard (1951) e de Claude Pichois e André Rousseau (1968) ${ }^{7}$ - são algumas das maiores expressões da chamada era clássica do comparatismo francês, do que se tornou conhecido como Escola Francesa de Literatura Comparada.

Tendo desempenhado papel fundamental no processo de consolidação da disciplina, e dominado o universo acadêmico por mais de meio século dentro e fora do país de origem, a Escola Francesa, apesar de hoje amplamente questionável em seus princípios e métodos, deixou cicatrizes no comparatismo que até recentemente se faziam sentir. A orientação dominante era de ordem histórica ou historiográfica, calcada na pesquisa de fontes e influências e restringindo o alcance da disciplina ao terreno das aproximações binárias e à constituição de famílias literárias. A Literatura Comparada era vista como um ramo da História Literária, e os autores, obras e movimentos, como manifestações de um contexto determinado, e portanto abordados por uma ótica extrínseca. O fenômeno literário não interessava em si mesmo, mas em suas relações quer com a série em que se insertava, quer com outros a que se assemelhava, e nesses casos a comparação dependia de um contato real e comprovado, documentado. Investigavam-se as filiações de uma obra, autor ou movimentos, e as influências que eles teria exercido sobre outros, e ficava-se, na maioria das vezes, em um plano puramente analógico-descritivo. É verdade que em alguns casos, tais estudos (cuja única diferença é a ênfase sobre o emissor influências - ou sobre o receptor - fontes) contribuíram para o melhor conhecimento de uma obra ou autor, revelando enganos e falácias, ou para avaliar a importância que estes tiveram em contextos posteriores. Mas o que ocorreu com frequiência foi o rastejo descritivista de traços epidérmicos, que não raro desaguou em labor de cunho simplesmente detetivesco.

\footnotetext{
${ }^{4}$ BETZ, Louis. La littérature comparée: essai bibliographique. Estrasburgo, 1904.

5 BALDENSPERGER, Fernand \& FRIEDERICH, Werner. Bibliography of Comparative Literature. Chapel Hill, Univ. of North Carolina Press, 1950.

6 VAN TIEGHEM, Paul. La littérature comparée. Paris, Colin, 1931.

${ }^{7}$ GUYARD, F. M. La littérature comparée. Paris, Presses Universitaires de France, 1951 e PICHOIS, Claude \& ROUSSEAU, André. La littérature comparée. Paris, Colin 1967. Este último teve uma reedição ampliada e atualizada, com a colaboração de mais um autor, Pierre Brunel, e o título Qu'est-ce que la littérature comparée? Paris, Colin, 1983.
} 
A ruptura com essa tradição vai ocorrer em 1958, durante o II Congresso da Associação Internacional de Literatura Comparada (AILC/ICLA), fundada poucos anos antes. Nesse Congresso, organizado por Werner Friederich, na Universidade de Carolina do Norte, em Chapel Hill (EUA), René Wellek apresenta uma conferência com o título provocativo de A crise da Literatura Comparada ${ }^{8}$, em que procede a um balanço da disciplina e investe contra suas fragilidades teóricas e a incapacidade de estabelecer até aquela época um objeto de estudo distinto e uma metodologia específica. O texto, verdadeiro libelo contra os pronunciamentos do grupo francês, representado por Baldensperger, Van Tieghem, Carré e Guyard, desperta imensa celeuma, e constitui uma espécie de ponto de partida do que vem a ser designado mais tarde, em oposição à Francesa, de Escola Americana de Literatura Comparada. Tais termos, observe-se, embora pátriogentílicos, não têm qualquer conotação de teor nacionalista. Antes, apontam para uma polêmica entre duas gerações de comparatistas: uma mais antiga, clássica, composta na maioria por professores e pesquisadores franceses, que encarava a disciplina por um viés predominantemente centrípeto, e outra mais recente, moderna, centrada principalmente em universidades norteamericanas, e que opunha à visão tradicional outra de cunho mais centrífugo.

Influenciado pelo Formalismo Russo, a Fenomenologia e o New Criticism norte-americano, Wellek critica com veemência os estudos de fontes e influências, de ordem extraliterária e baseados em princípios causalistas, e propõe uma análise centrada primordialmente no texto. Entretanto, ele não se atém à postura imanentista dessas correntes; ao contrário, considera um complemento fundamental o estudo das relações entre o texto e o contexto em que este fora produzido. Sua crítica incide sobre o historicismo tradicional, mas não sobre a dimensão histórica, que não deve jamais estar ausente na abordagem do fenômeno literário. Além disso, os estudos de fontes e influências limitavam-se na maioria das vezes a estéreis paralelismos, resultantes de mera caça às semelhanças. Wellek condena a perspectiva predominantemente descritivista de tais estudos e afirma que comparatismo e crítica não podem andar separados. Do mesmo modo, insurge-se contra a distinção entre Literatura Comparada e Literatura Geral e o ressurgimento da velha Stoffgeschichte alemã, e aceita a possibilidade de estudos comparatistas no interior de uma única literatura, contanto que a abordagem adotada tenha uma dimensão crítico-teórica que transcenda as fronteiras dessa literatura. Todos esses aspectos formam juntos a base da cisão entre uma suposta orientação norte-americana e a francesa clássica, e fazem do autor uma espécie de prógono da nova Literatura Comparada. Contudo, assinale-se que, a despeito das diferenças significativas que ponteiam essas duas escolas, a incompatibilidade entre elas não é irredutível.

8 WELLEK, René. The crises of Comparative Literature. In: FRIEDERICH, Werner, ed. Comparative Literature: Proceedings of the II Congress of the ICLA. Chapel Hill, Univ. of North Carolina Press, 1959, v. 1, p. 149-60. Repl. in WELLEK, René. Concepts of Criticism. New Haven, Yale Univ. Press, 1963, p. 282-95. 
Basta lembrar o caso de Etiemble, que sucede a Carré na Sorbonne, e que, pelo questionamento empreendido contra o comparatismo tradicional e a crítica desencadeada contra toda sorte de eurocentrismo, chega a aproximarse mais dos americanos do que de seus pares na França ${ }^{9}$.

Embora os autores que integram a chamada Escola Americana de Literatura Comparada não constituam um grupo coeso nem disponham de um programa estabelecido, fortes denominadores comuns, distinguíveis na atuação desses autores, justificam o uso do termo. Além dos rasgos já apontados na proposta de Wellek, registrem-se o tônus mais eclético da nova escola e sua capacidade de absorção de noções teóricas diversas. Tais aspectos ampliam consideravelmente o escopo da Literatura Comparada, conferindo-lhe um caráter mais internacional, que a leva a incluir outras literaturas até então alheias ao cânone da tradição ocidental, e mais interdisciplinar, que a aproxima não só das demais formas de atividade artística, como ainda de outras esferas do conhecimento. Tomando sempre por base o texto, mas levando também em conta suas relações com o contexto histórico-cultural, a Escola Americana aborda o fenômeno literário por caminhos diversos, mas ao mesmo tempo chamando atenção para a importância de uma metodologia científica, que não lhe permita incorrer em simples sistema de trocas bilaterais. Nessa nova fase, os tradicionais estudos de fontes e influências sofrem um embate decisivo e as barreiras entre comparatismo e crítica tornam-se cada vez mais tênues. Contudo, nem todos os germes da tradição são lançados por terra, permanecendo ainda entre outras coisas o cunho universalizante das propostas - o seu caráter de grand récit, para empregar a expressão de Lyotard $^{10}$ - e o tom, porquanto camuflado, ainda iniludivelmente etnocêntrico do discurso.

Além dessas duas escolas de Literatura Comparada, houve também, no percurso de autodefinição e consolidação da disciplina, outras vozes, em grupo ou isoladas, que, embora em menor escala, prestaram valiosa contribuição à sua formação, e a que, portanto, não pode faltar menção. Entre as primeiras, vale mencionar o grupo de estudiosos eslavos, também chamado de Escola Soviética, e representado sobretudo pelas figuras de Victor Zhirmunsky e Dionyz Durisin, que, somando a influências do Formalismo Russo preocupações de ordem social, desenvolveu um sistema de analogias tipológicas e chamou atenção para os topoi da tradição popular e legendária. E entre as vozes isoladas, citem-se figuras como Robert Escarpit, dentro da própria França, que projetou novas luzes sobre o comparatismo, abordando-o por uma ótica sociológica e realizando pesquisas com o público ledor, que antecipam questões posteriormente retomadas e reelaboradas pelos teóricos da Estética da Recepção, e Claudio Guillén e Guillermo de Torre, que,

9 Ver ETIEMBLE, René. Comparaison n'est pas raison. Paris, Presses Universitaires de France, 1963.

${ }^{10}$ LYOTARD, Jean-François. La condition postmoderne. Paris, Minuit, 1979. 
situados, pela sua origem hispânica, fora do eixo central da Literatura Comparada, ergueram-se como críticos combatentes do etnocentrismo.

A maior permeabilidade da Escola Americana e as contribuições dessas vozes isoladas conferiram novo impulso ao comparatismo, que deixou de lado a perspectiva historicista tradicional e seu correlato - os velhos estudos de fontes e influências - e passou a ocupar-se cada vez mais do texto literário e das relações interliterárias e interdisciplinares. No entanto, a amplitude que adquiriram os estudos comparatistas dos anos 70 até o presente deve muito à voga da Teoria Literária nesse período, sobretudo às ondas estruturalista e pós-estruturalista ou desconstrutivista, que varreram o meio intelectual ocidental e os estudos interdisciplinares, que se expandiram consideravelmente na mesma época, conquistando espaços até então reservados a determinadas áreas do conhecimento. Ao contrário do que se poderia supor, a Literatura Comparada e a Teoria Literária não se antagonizam em momento algum; antes complementam-se, e não podem prescindir uma da outra. Toda teorização sobre uma obra ou obras literárias pressupõe necessariamente um atividade comparatista, ainda que num plano intertextual não explícito, e todo estudo comparatista sério conflui para uma reflexão de ordem teórica e crítica; caso contrário, corre o risco de ater-se a mero descritivismo. A Teoria, a Crítica e a Literatura Comparada constituem disciplinas acadêmicas distintas pela ênfase que é dada ao objeto da pesquisa em cada uma delas, mas a atuação de uma sobre a outra é de tal modo significativa, que o diálogo entre elas é fator indispensável.

Não cabe aqui detalhar a contribuição que cada uma das correntes teórico-críticas da segunda metade do século XX aportou para a Literatura Comparada, desde o Estruturalismo e a Semiologia, passando pela Estética da Recepção e pela releitura a que se procedeu do Marxismo e da Psicanálise, até as visões mais recentes do Desconstrutivismo e da Nova História, mas é mister assinalar que, graças a este intercurso, o comparatismo ganhou uma dimensão, que se expressa hoje na multiplicidade de caminhos com que ele dialoga com a obra literária. Consciente - sobretudo depois da grande penetração dessas duas últimas correntes - da sua própria situação de discurso, condicionado a uma realidade histórico-cultural determinada, e portanto passível de questionamento, o comparatismo vem pondo em xeque seus pressupostos básicos, de teor etnocêntrico, e reformulando-se constantemente. Agora, o ideal de universalização, que por tanto tempo norteou os estudos comparatistas, segundo o qual a literatura constituía uma espécie de força enobrecedora da humanidade, acima de qualquer barreira de ordem linguística ou nacional, revela-se como mera utopia, e o centro de gravidade desses estudos se desloca justamente para aquele aspecto relegado a plano secundário pela tradição: a especificidade das literaturas nacionais ${ }^{11}$.

11 Para uma discussão mais ampla dessa questão, ver BASSNETT, Susan. Comparative Literature. A Critical Introduction. Oxford, Blackwell, 1993. 
Os estudos interdisciplinares desenvolvidos nas duas últimas décadas, máxime os chamados estudos pós-coloniais, abalaram, do mesmo modo que as correntes teórico-críticas mais recentes, as bases da Literatura Comparada, e as grandes modificações que eles ocasionaram emergem exatamente daqueles contextos literários até então vistos como periféricos pelos comparatistas. Nesses locais, onde não há nenhum senso de incompatibilidade entre Literaturas nacionais e Literatura Comparada, os estudos comparativos têm-se associado com frequiência a questões de identidade nacional e cultural e têm adquirido uma feição política bastante acentuada. O desafio levantado por críticos como Edward Said e Homi Bhabha $^{12}$ ao processo sistemático instituído pelas nações colonizadoras de inventar outras culturas passa a figurar da ordem do dia nesses contextos, e o desvio de olhar torna-se um ponto fulcral em qualquer abordagem comparatista. Ao invés de tomar-se como referência o modelo europeu e olhar para a literatura nacional ou local pela perspectiva dele, o fundamental agora é partir do próprio solo, do locus onde se situa o pesquisador, e mirar a tradição forânea pela sua ótica. É nisto que reside a tônica do novo comparatismo, que se vem desenvolvendo com tanto vigor e dinamismo em pontos diversos da Ásia, como a Índia e a China, em países diferentes da África, e na América Latina, de maneira geral.

Esta nova orientação da Literatura Comparada, proveniente de esfera distinta da européia e norte-americana, traz à tona uma série de problemas, que agora se incorporam à agenda da disciplina: questões como a das relações entre uma tradição local e outra importada, das implicações políticas da influência cultural, da necessidade de revisão do cânone literário e dos critérios de periodização. Um curso sobre as grandes obras da literatura, por exemplo, não se pode mais circunscrever ao cânone instituído pela tradição ocidental, que dominou durante tanto tempo o meio acadêmico em geral, nem tampouco uma história literária se pode mais constituir tomando como referência a periodização usual. Tanto o cânone quanto o modelo europeu tradicional de periodização literária sempre se basearam em premissas que ou ignoravam por completo toda produção exterior a um círculo geográfico restrito, ou tocavam tangencialmente nessa produção, incluindo, como uma espécie de concessão, no referido círculo, uma ou outra de suas manifestações.

As reações contra o etnocentrismo já são na realidade uma constante na Literatura Comparada desde os tempos de Wellek e Etiemble, e se lançarmos uma mirada retrospectiva ao campo de atuação da disciplina, veremos que elas têm aflorado de maneira variada ao longo de sua evolução. Contudo, na maioria dos casos, tais reações se têm manifestado à base de uma oposição binária, que continua paradoxalmente tomando como referência o elemento europeu. É aí que reside sobretudo o valor da contribuição dos

12 Ver SAID, Edward. Orientalismo: o Oriente como invenção do Ocidente. Trad. Tomás R. Bueno. São Paulo, Cia. das Letras, 1990 e BHABHA, Homi, ed. Nation and Narration. Londres, Routledge, 1990. 
estudos pós-colonialistas para o domínio do comparatismo: questiona-se a hegemonia das culturas colonizadoras, mas se reconhece e explora a pluralidade de caminhos que se abrem como resultado do contato entre colonizador e colonizado. O comparatista agora, ao contrário do que ocorria nos estágios anteriores da disciplina, vê-se diante de um labirinto, gerado pela desierarquização dos elementos envolvidos no processo da comparação, e sua tarefa maior reside precisamente nessa construção em aberto que ele irá realizar, nessa viagem de descoberta sem marcos definidos. A Literatura Comparada é hoje uma seara ampla e movediça, com inúmeras possibilidades de exploração, que deixou de lado o anseio totalizador de suas fases de formação e consolidação, e se ergue como um diálogo transcultural calcado na aceitação das diferenças e numa visão de mundo em que categorias como as de centro e periferia sofreram significativa reestruturação.

\section{Bibliografia}

BHABHA, Homi, ed. Nation and narration. Londres, Routledge, 1990.

BALDENSPERGER, Fernand \& FRIEDERICH, Werner. Bibliography of comparative literature. Chapel Hill, Univ. of North Carolina Press, 1950.

BASSNETT, Susan. Comparative literature. A critical introduction. Oxford, Blackwell, 1993.

BETZ, Louis. La littérature comparée: essai bibliographique. Estrasburgo, 1904.

CLEMENTS, Robert J. Comparative literature as academic discipline. New York, MLA, 1978.

ETIEMBLE, René. Comparaison n'est pas raison. Paris, Presses Universitaires de France, 1963.

GUYARD, F. M. La littérature comparée. Paris, Presses Universitaires de France, 1951.

LYOTARD, Jean-François. La condition postmoderne. Paris, Minuit, 1979.

PICHOIS, Claude \& ROUSSEAU, André. La littérature comparée. Paris, Colin, 1967.

SAID, Edward. Orientalismo: o oriente como invenção do ocidente. Trad. Tomás R. Bueno. São Paulo, Cia. das Letras, 1990.

POSNETT, H. M. Comparative literature. (1886); rpt New York, Johnson Reprints, 1970.

VAN TIEGHEM, Paul. La littérature comparée. Paris, Colin, 1931.

WEISTEIN, Ulrich. Comparative literature and literary theory. Bloomington, Indiana Univ. Press, 1973.

WELLEK, René. The crises of comparative literature. In: FRIEDERICH, Werner, ed. Comparative literature: Proceedings of the II Congress of 
the ICLA. Chapel Hill, Univ. of North Carolina Press, v. 1, p. 149-60, 1959. Repl. in WELLEK, René. Concepts of criticism. New Haven, Yale Univ. Press, p. 282-95, 1963. 